\title{
FORMAÇÃO CIDADÃ E RESPONSABILIDADE SOCIAL: COMO A ONG ENGENHEIROS SEM FRONTEIRAS PODE CONTRIBUIR PARA O ATENDIMENTO DAS NOVAS DIRETRIZES CURRICULARES NACIONAIS DE ENGENHARIA.
}

Diana Fiori Rubim - diana.rubim@engenharia.ufjf.br

Universidade Federal de Juiz de Fora, Faculdade de Engenharia

Rua José Lourenço Kelmer, s/n - São Pedro

36036-900 - Juiz de Fora - MG

Maria Aparecida Steinherz Hippert - aparecida.hippert@ ufjf.edu.br

Universidade Federal de Juiz de Fora, Faculdade de Engenharia

Rua José Lourenço Kelmer, s/n - São Pedro

36036-900 - Juiz de Fora - MG

Resumo: O presente artigo tem como objetivo fazer um estudo das novas Diretrizes Curriculares Nacionais (DCNs) de Engenharia, a fim de identificar quais são suas demandas, sobretudo aquelas que dizem respeito à formação cidadã e responsabilidade social, e além disso, investigar o potencial da ONG Engenheiros Sem Fronteiras como agente de atendimento de tais demandas. Para tal, foi realizada uma revisão bibliográfica. Como conclusão, foi possível verificar que a Universidade Federal de Juiz de Fora pode estabelecer uma relação de benefício mútuo com o Engenheiros Sem Fronteiras local, isto pois, ao passo que ela confere parceria institucional e sede para a ONG, os alunos que se tornam membros da mesma são capazes de desenvolver as competências e atingir o perfil do egresso esperado através das novas DCNs, recebendo uma formação humanística e crítica, através de trabalhos em equipes multidisciplinares e aprendizagem ativa.

Palavras-chave: Formação Cidadã. Responsabilidade Social. Engenheiros Sem Fronteiras. 


\section{INTRODUÇÃO}

O mercado de engenharia tem exigido cada vez mais profissionais multidisciplinares, com alta capacidade de resolução de problemas e com base técnica sólida. Por outro lado, Pereira e Piolho (2017) apontam que existem obstáculos para um ensino que entregue uma visão mais ampla da engenharia, e, dentre outras questões, estão a falta de atividades interdisciplinares que possam associar a formação específica com o contexto social.

De acordo com Bazzo (2010), os objetivos do ensino em engenharia não vêm sendo cumpridos em totalidade, uma vez que, de maneira geral, as condições para que os alunos adquiriam as habilidades e competências necessárias à sua formação não são fornecidas. Estas dizem respeito, principalmente, à formação de um profissional que visa atender os anseios da sociedade contemporânea, pautada em questões políticas, econômicas, sociais e ambientais.

Segundo Menestrina e Bazzo (2008), a formação cidadã do profissional de engenharia é uma meta que se fortalece diariamente, ao menos no campo teórico. Contudo, tais metas devem ser convertidas em ações. Os autores definem formação cidadã como sendo:

\footnotetext{
Inclusão dos acadêmicos nas problemáticas das comunidades e o estabelecimento por ele e por todos os envolvidos no processo de aprendizagem de pontes entre os conteúdos ministrados na sua graduação e as relações que podem constituir entre a sua profissionalização e a Sociedade (MENESTRINA; BAZZZO, 2008, p. 4).
}

Frente a este cenário, as Diretrizes Curriculares Nacionais (DCN) propõem uma organização curricular embasada nas transformações que ocorrem no ambiente científico e em processos sociais, envolvendo, portanto, a interdisciplinaridade; uma formação alinhada com a realidade social; a perspectiva de uma educação continuada e vínculo entre teoria e prática, o qual deve estar presente na tríade universitária: ensino, pesquisa e extensão (BRASIL, 2002).

Dessa maneira, o objetivo do presente artigo é fazer uma síntese das demandas impostas através das novas DCNs, com enfoque para a formação cidadã e responsabilidade social do Engenheiro. Além disso, pretende-se buscar exemplos práticos de como esse estímulo vêm ocorrendo dentro da Faculdade de Engenharia da Universidade Federal de Juiz de Fora. O estudo em questão trata da ONG Engenheiros Sem Fronteiras - JF.

\section{DIRETRIZES CURRICULARES NACIONAIS DA ENGENHARIA}

De acordo com o Artigo $2^{\circ}$ da Resolução no 2, de 24 de Abril de 2019, publicada no Diário Oficial da União, as Diretrizes Curriculares Nacionais (DCNs) tem como objetivo organizar e contribuir para o desenvolvimento e avaliação dos cursos de graduação em Engenharia das Instituições de Ensino Superior (IES) em âmbito nacional, e, para tal, são definidos princípios, fundamentos, condições e finalidades, os quais são estabelecidos pela Câmara de Educação Superior do Conselho Nacional de Educação (CES/CNE) (BRASIL, 2019).

Após um processo envolvendo discussões de entidades de representação acadêmica, industrial e profissional, tais como Associação Brasileira de Educação em Engenharia (ABENGE), a Confederação Nacional da Indústria (CNI) e o Conselho Federal de Engenharia e Agronomia (CONFEA), as DCNs da Engenharia sofreram atualização em 2019. As novas 
DCNs permitem maior flexibilização dos projetos pedagógicos e conduzem uma mudança na concepção da formação, para que ela não seja construída apenas por conteúdos, mas também baseada em competências (BRASIL, 2019).

Dessa maneira, os cursos de engenharia em funcionamento possuem um prazo de até 3 anos a partir da data da publicação da Resolução - 24 de abril de 2019 - para implementação das novas DCNs, podendo essa ser feita de maneira gradual, avançando período por período ou imediatamente, através do consentimento dos alunos. Para seu devido aperfeiçoamento, o desenvolvimento das novas DCNs deve ser acompanhado, monitorado e avaliado pela IES e pelos processos externos de avaliação e regulação conduzidos pelo Ministério da Educação (MEC) (BRASIL, 2019).

O documento que institui as novas DCNs é dividido segundo a estruturação abaixo:

- CAPÍTULO I - das disposições preliminares

- CAPÍTULO II - do perfil e competências esperadas do egresso

- CAPITULO III - da organização do curso de graduação em engenharia

- CAPÍTULO IV - da avaliação das atividades

- CAPÍTULO V - do corpo docente

- CAPÍTULO VI - das disposições finais e transitórias

De maneira geral, o incentivo a atividades práticas visando a criatividade e espírito de inovação, o uso de metodologias de aprendizagem ativa, a diversificação dos métodos de avaliação, o acolhimento dos ingressantes, bem como a valorização e formação da atividade docente foram preocupações evidenciadas na resolução (WATANABE et al., 2019).

Como citado anteriormente, o presente artigo tem como objetivo investigar quais as demandas advindas das novas DCNs dizem respeito a responsabilidade social e formação cidadã, e, portanto, a revisão será recortada para o Capítulo II da resolução cujos temas abordados são o perfil e competências esperadas do egresso. 


\subsection{Perfil e competências esperadas do egresso}

O Capítulo II das novas DCNs de Engenharia é composto por 3 artigos, artigos $3^{\circ}$, $4^{\circ}$. e $5^{\circ}$., apresentados nos Quadros 1, 2 e 3.

Quadro 1 - Art. 3: Perfil do egresso do curso de Engenharia

\begin{tabular}{|c|l|}
\hline I & $\begin{array}{l}\text { ter visão holística e humanista, ser crítico, reflexivo, criativo, cooperativo e } \\
\text { ético e com forte formação técnica }\end{array}$ \\
\hline II & $\begin{array}{l}\text { estar apto a pesquisar, desenvolver, adaptar e utilizar novas tecnologias, } \\
\text { com atuação inovadora e empreendedora; }\end{array}$ \\
\hline III & $\begin{array}{l}\text { ser capaz de reconhecer as necessidades dos usuários, formular, analisar e } \\
\text { resolver, de forma criativa, os problemas de Engenharia; }\end{array}$ \\
\hline IV & adotar perspectivas multidisciplinares e transdisciplinares em sua prática; \\
\hline V & $\begin{array}{l}\text { considerar os aspectos globais, políticos, econômicos, sociais, ambientais, } \\
\text { culturais e de segurança e saúde no trabalho; }\end{array}$ \\
\hline VI & $\begin{array}{l}\text { atuar com isenção e comprometimento com a responsabilidade social e com } \\
\text { o desenvolvimento sustentável. }\end{array}$ \\
\hline
\end{tabular}

Fonte: (BRASIL, 2019)

Quadro 2 - Art. 4: Competências que os cursos devem proporcionar ao longo da formação

\begin{tabular}{|c|c|}
\hline I & $\begin{array}{l}\text { formular e conceber soluções desejáveis de engenharia, analisando e } \\
\text { compreendendo os usuários dessas soluções e seu contexto: }\end{array}$ \\
\hline II & $\begin{array}{l}\text { analisar e compreender os fenômenos físicos e químicos por meio de } \\
\text { modelos simbólicos, físicos e outros, verificados e validados por } \\
\text { experimentação }\end{array}$ \\
\hline III & $\begin{array}{l}\text { conceber, projetar e analisar sistemas, produtos (bens e serviços), } \\
\text { componentes ou processos: }\end{array}$ \\
\hline IV & implantar, supervisionar e controlar as soluções de Engenharia: \\
\hline V & comunicar-se eficazmente nas formas escrita, oral e gráfica: \\
\hline VI & trabalhar e liderar equipes multidisciplinares \\
\hline VII & $\begin{array}{l}\text { conhecer e aplicar com ética a legislação e os atos normativos no âmbito do } \\
\text { exercício da profissão: }\end{array}$ \\
\hline
\end{tabular}




\begin{tabular}{|l|l|}
\hline VIII & $\begin{array}{l}\text { aprender de forma autônoma e lidar com situações e contextos complexos, } \\
\text { atualizando-se em relação aos avanços da ciência, da tecnologia e aos } \\
\text { desafios da inovação: }\end{array}$
\end{tabular}

Fonte: (BRASIL, 2019)

Quadro 3 - Art. 5: Possíveis áreas de atuação do egresso

\begin{tabular}{|c|l|}
\hline I & $\begin{array}{l}\text { atuação em todo o ciclo de vida e contexto do projeto de produtos (bens e } \\
\text { serviços) e de seus componentes, sistemas e processos produtivos, inclusive } \\
\text { inovando-os }\end{array}$ \\
\hline II & $\begin{array}{l}\text { atuação em todo o ciclo de vida e contexto de empreendimentos, inclusive } \\
\text { na sua gestão e manutenção; }\end{array}$ \\
\hline III & $\begin{array}{l}\text { atuação na formação e atualização de futuros engenheiros e profissionais } \\
\text { envolvidos em projetos de produtos (bens e serviços) e empreendimentos. }\end{array}$ \\
\hline
\end{tabular}

Fonte: (BRASIL, 2019)

É evidente que o atendimento às disposições acima apresentadas não será alcançado por meio do conhecimento apresentado apenas em sala de aula. Por essa razão, é de extrema importância que o aluno tenha contato com atividades extraclasse, uma vez que tais experiências fomentam contextos nos quais ele estará sujeito aos estímulos para desenvolver as competências esperadas do perfil do egresso.

\section{ONG ENGENHEIROS SEM FRONTEIRAS - JUIZ DE FORA}

Os núcleos da rede Engenheiros Sem Fronteiras - Brasil (ESF-Brasil) realizam projetos de engenharia e arquitetura e outras áreas, bem como ações sociais, para a população em vulnerabilidade socioeconômica. Também fazem parte da rede o Engineers Without Borders International, a qual está presente em 65 países do mundo. Os pilares do ESF-Brasil são: engenharia, sustentabilidade, educação e voluntariado. Estima-se que 84 mil vidas tenham sido impactadas desde 2010 aqui no Brasil (ESF-Brasil, 2020). Portanto, o ESF-Brasil atua como suporte na criação e homologação de novos núcleos, capitação de recursos e parcerias para a rede, bem como institui diretrizes a nível nacional que todos os núcleos devem atender. Contudo, cada núcleo possui autonomia e está inserido em contextos e especificidades diferentes. Dessa forma, esse estudo está limitado ao núcleo de Juiz de Fora.

O núcleo Engenheiros Sem Fronteiras - Juiz de Fora (ESF-JF) foi criado em 2015 por alunos do curso de Engenharia de Produção da Universidade Federal de Juiz de Fora. Apesar da ONG não possuir obrigatoriedade de vínculo com instituições de ensino superior, esse tipo de parceria contribui para a manutenção do núcleo. No caso do ESF-JF, existe uma parceria institucional 
com a UFJF, que hoje tem a ONG como um projeto cadastrado na Pro Reitoria de Extensão, além de fornecer aos alunos um espaço físico, que é utilizado como sede.

Os projetos realizados são prospectados em instituições e comunidades em situação de vulnerabilidade social, sendo hoje mais de 70 finalizados e mais de 7.500 pessoas impactadas. Por diretrizes do Engineers Without Borders (EWB) e através do Pacto Global, os projetos estão em acordo com os Objetivos de Desenvolvimento Sustentável (ODS) da ONU e são divididos em 4 eixos:

- Educacional: Voltados à capacitação técnica profissional, melhoria no ensino, formação interpessoal de estudantes de engenharia e ações de conscientização.

- Gestão e Empreendedorismo: Relacionados com e organização e ferramentas de gestão de instituições, através do fomento a práticas e atividades empreendedoras.

- Infraestrutura e Assistência Básica: Com foco em amenizar as necessidades do indivíduo e da infraestrutura de instituições, como arrecadações de alimentos e roupas, pintura, reformas e projetos de usucapião, arquitetônico, elétrico e hidrossanitário.

- Sustentabilidade: Voltados ao uso eficiente dos recursos como aquecimento solar, reaproveitamento de água, reciclagem e destinação de resíduos, hortas comunitárias e tratamento de água e esgoto.

\subsection{Organograma e Estruturação interna}

O núcleo ESF-JF conta com estudantes de arquitetura, engenharias e ainda com editais abertos para profissionais graduados e também de outras áreas do conhecimento, tais como: jornalismo, publicidade, design, artes visuais, tecnologia da informação, psicologia e recursos humanos. Atualmente o organograma é dividido como apresentado na Figura 1.

Figura 1 - Organograma do ESF-JF

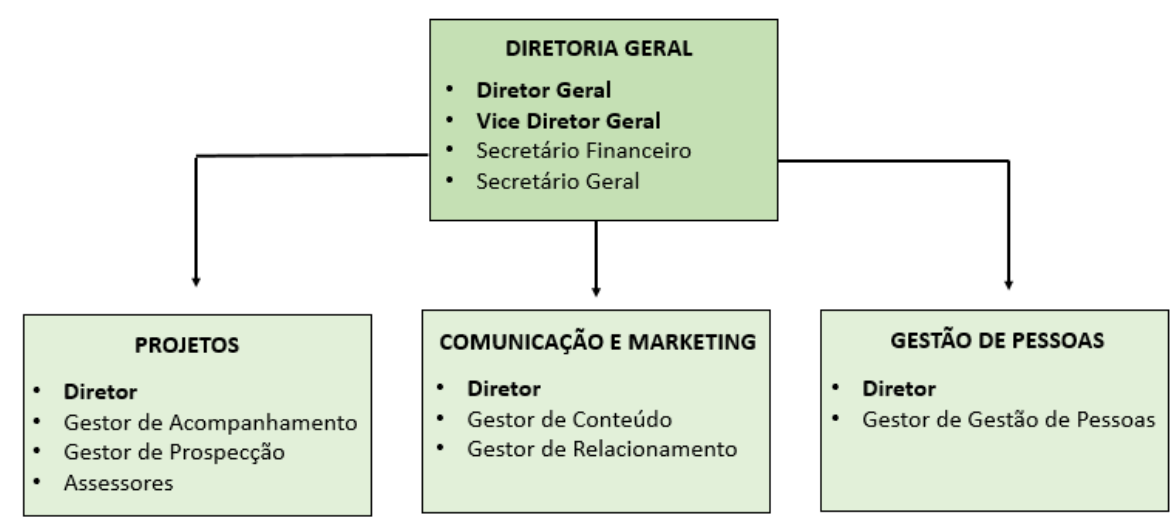

Fonte: As autoras (2020) 


\subsection{Atuação do estudante no ESF-JF}

Os projetos realizados pelo núcleo são captados pela equipe de prospecção e levados até a Diretoria de Projetos. Neste momento inicial, onde ocorre a visita técnica, os membros do núcleo realizam o primeiro contato com beneficiário, o qual possui extrema importância, isso pois é imprescindível: i) entender qual é de fato a demanda a ser atendida e ii) diagnosticar como a ONG pode atuar em busca de sanar o problema.

Uma vez aprovado, o projeto se torna disponível para os assessores demonstrarem intenção para sua execução. A princípio é feita a candidatura para a gerência do projeto. Dessa maneira, o gerente torna-se o "líder" do projeto, responsável por, dentre outras coisas: i) preencher toda a documentação e relatório do projeto, ii) elaborar o formulário para preenchimento da equipe do projeto - ou seja, escolher outros assessores que irão executá-lo, iii) elaborar cronograma e planejamento do projeto, bem como prestar seu andamento ao gestor de acompanhamento e iv) delegar tarefas, motivar a equipe e juntos executarem o projeto.

É bastante comum que durante a execução dos projetos a equipe não tenha domínio técnico prévio do projeto a ser executado. Isso faz com que seja estimulada uma aprendizagem ativa, a qual ocorre por meio de pesquisas na literatura disponível na internet, busca por cursos ou capacitações, trocas de experiências com membros ativos ou egressos que já realizaram o projeto e também suporte dos professores da universidade que se tornaram colaboradores do núcleo.

No decorrer do projeto, a criatividade dos membros é estimulada, pois muitas vezes é necessário atender uma demanda através de poucos recursos financeiros, fazendo com que a equipe pense em soluções inovadoras. Outro fato que contribui para isso é a equipe multidisciplinar, ou seja, alunos de modalidades de engenharia diferentes trabalhando juntos para uma solução que por vezes não é da sua área de conhecimento.

Ao final do projeto, é necessário preencher o documento do projeto, descrevendo cada uma de suas etapas e pontos de atenção para projetos futuros. Uma situação recorrente dentro da ONG é o desejo por executar projetos de fácil replicabilidade (Projetos Modelo). Por isso, é estimulada a publicação de trabalhos acadêmicos divulgando o projeto, bem como a busca por editais que fomentem e custeiem sua execução, fazendo com que a escrita e domínio oral se torne muito relevante.

Ademais, além da experiência técnica advinda do cargo de assessor de projetos, o aluno possui oportunidade de crescimento dentro da ONG, podendo ocupar cargos de liderança, desenvolvendo competências administrativas e organizacionais e contribuindo para formação de uma visão sistêmica do núcleo.

\section{METODOLOGIA}

Este trabalho se consiste em uma revisão bibliográfica, baseada principalmente nos anais disponíveis de outras edições do Congresso Brasileiro de Educação em Engenharia (COBENGE), bem como em documentos internos e sites da rede Engenheiros Sem Fronteiras. 
Além disso, o trabalho conta com o conhecimento pessoal de uma das autoras, a qual é membra egressa do ESF-JF.

\section{RESULTADOS E DISCUSSÕES}

Através na análise da atuação do membro participante do ESF-JF, torna-se evidente que seu trabalho dentro da ONG contempla em totalidade as diretrizes esperadas pelo perfil do egresso em engenharia, bem como oferece as competências que os cursos devem oferecer ao longo da graduação, as quais estão dispostas nos Artigos 3 e 4 do Capítulo II das novas DCNs.

Desde a prospecção do projeto, planejamento, execução e documentação, bem como no crescimento do membro dentro da ONG, o discente desenvolve visão holística e humanística, criatividade, cooperação e capacitação técnica. Além disso, é indispensável que o aluno seja capaz de reconhecer as necessidades do beneficiário, além de ser estimulado a pesquisa e desenvolvimento de soluções inovadoras para atendimento às situações problema. No decorrer da execução, os projetos contam com equipes formadas por alunos das engenharias civil, elétrica, ambiental, mecânica e/ou produção, além da oportunidade do contato com alunos da arquitetura e outras áreas. O departamento de projetos, através da equipe de prospecção, realiza um estudo de quais serão os focos de ataque da gestão, concentrando-se nos bairros em maior vulnerabilidade da cidade de Juiz de Fora, levando em consideração aspectos econômicos, sociais e ambientais. Como diretriz a nível internacional, os projetos devem estar alinhados com as ODS, o que garante desde o início do projeto o comprometimento com o desenvolvimento sustentável e responsabilidade social.

Uma vez observado o papel realizado pelos núcleos Engenheiros Sem Fronteiras no que diz respeito à formação cidadã do estudante de engenharia, torna-se relevante uma maior aproximação da Universidade com os núcleos locais, como ocorre no caso de Juiz de Fora. O apoio institucional da IES contribui tanto para a criação quanto para a manutenção de um núcleo ESF, e a partir disso, pode-se estabelecer uma relação de benefício mútuo, uma vez que a instituição pode vincular o trabalho da ONG ao atendimento das novas DCNs.

\section{CONSIDERAÇÕES FINAIS}

Os desafios do engenheiro do amanhã são muitos. Além da demanda por profissionais altamente capacitados e que entreguem produtos de engenharia de maior qualidade e eficiência, o estímulo por uma atuação inserida no campo socioambiental tem-se tornado cada vez mais urgente.

Soluções para moradia, energia elétrica, abastecimento, saneamento, mobilidade urbana e preservação ambiental são áreas das mais diversas modalidades de Engenharia, contudo, é de praxe que a oferta de soluções nessas áreas seja entregue apenas para a população mais favorecida. Contudo, além das imposições claras das novas DCNs para uma formação cidadã, humanística e com presença de responsabilidade social, é impossível não mencionar a pandemia 
do COVID-19, que escancarou a necessidade desses serviços pelas famílias em vulnerabilidade social, como melhorias habitacionais e acesso a água.

Dessa maneira, para que o futuro egresso considere uma atuação que vá de encontro à população mais carente, é imprescindível que esse estímulo ocorra ao longo de sua graduação. Com isso, o presente trabalho alcançou seu objetivo de verificar que a ONG Engenheiros Sem Fronteiras, através de um estudo específico do caso do núcleo de Juiz de Fora, é capaz de promover estímulo e contribuir para o alcance das demandas impostas pelo MEC.

\section{REFERÊNCIAS}

BAZZO, W. A. Ciência, tecnologia e sociedade e o contexto da educação tecnológica. 2a ed., Florianópolis: Ed. UFSC. 2010.

BRASIL. Ministério da Educação. Conselho Nacional de Educação. Câmara de Educação Superior. Resolução ${ }^{\circ} 11$, de 11 de março de 2002. Institui as Diretrizes Curriculares Nacionais do Curso de Graduação em Engenharia. Brasília: Ministério da Educação, 2002. Disponível em: http://portal.mec.gov.br/cne/arquivos/pdf/ CES112002.pdf. Acesso em: 05 ago. 2020.

BRASIL. Ministério da Educação. Conselho Nacional de Educação. Câmara de Educação Superior. Resolução $\mathrm{n}^{\circ}$ 2, de 24 de abril de 2019. Institui as Diretrizes Curriculares Nacionais do Curso de Graduação em Engenharia. 2019. Brasília: Ministério da Educação, 2019. Disponível em: http://portal.mec.gov.br/index.php? option=com_docman\&view=download\&alias=112681-rces002 19\&category_slug= abril2019-pdf\&Itemid=30192. Acesso em: 05 ago. 2020.

MENESTRINA, T. C.; BAZZO, W. A. Ciência, tecnologia e sociedade e formação do engenheiro: análise da legislação vigente. Revista Brasileira de Ensino de Ciência e Tecnologia, v.1, n.2, p. 1-18, mai./ago. 2008.

Núcleo Juiz de Fora. Engenheiros Sem Fronteiras - Brasil, 2020. Disponível em: https://esf.org.br/nucleo-juiz-de-fora/ . Acesso em: 05 ago. 2020.

PEREIRA, Vágner R. de A.; PIOLHO, Francisco de A. P. Engenharia: uma visão ampliada da profissão. In: XLV Congresso Brasileiro de Educação em Engenharia, 2017, Joinville. Anais... Distrito Federal, 2017.

Projetos. Engenheiros Sem Fronteiras - Brasil, 2020. Disponível em: https://esf.org.br/projetos/. Acesso em: 05 ago. 2020.

WATANABE, Flávio Y.; ANTONIALLI, Armando I. S.; VENTURA, Carlos E. H.; PAZIANI, Fabrício T.; ARAUJO, Luis A. O.; SHIKI, Sidney B.; FRANCO, Vitor R. As Novas DCNs De Engenharia: Desafios, Oportunidades e Proposições. In: Congresso de Ensino de Graduação, 2019, São Carlos. Anais... São Carlos, 2019. 


\title{
CITIZEN FORMATION AND SOCIAL RESPONSIBILITY: HOW THE NGO ENGINEERS WITHOUT FRONTIERS CAN CONTRIBUTE TO THE SERVICE OF THE NEW NATIONAL CURRICULUM ENGINEERING GUIDELINES.
}

\begin{abstract}
This article aims to make a study of the new National Curriculum Guidelines (DCNs) of Engineering, in order to identify what are their demands, especially those related to citizen education and social responsibility, and in addition, to investigate the potential of the NGO Engineers Without Borders as an agent to meet such demands. For this, a bibliographic review was carried out. As a conclusion, it was possible to verify that the Federal University of Juiz de Fora can establish a relationship of mutual benefit with the local Engineers Without Borders, because while it confers institutional partnership and headquarters for the NGO, the students that become members are able to develop the skills and reach the expected egress profile through the new DCNs, receiving humanistic and critical training, through work in multidisciplinary teams and active learning.
\end{abstract}

Keywords: Citizen Formation. Social Responsability. Engineers Without Borders. 